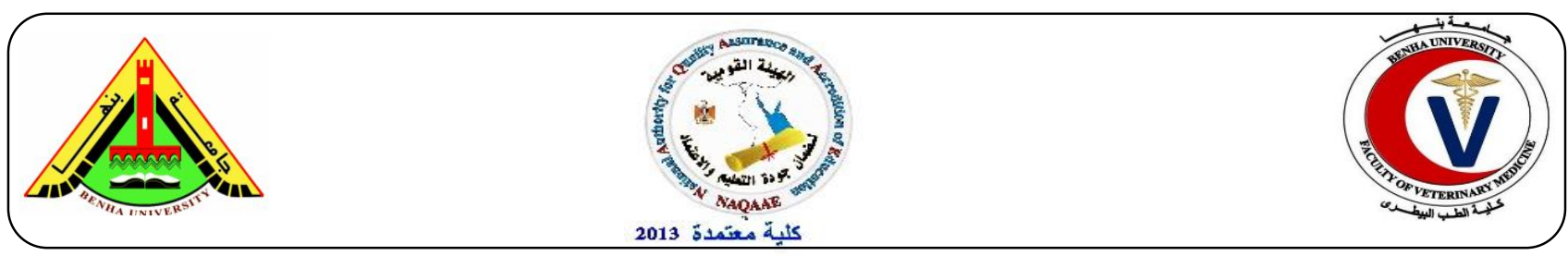

\title{
Alternative Approaches for Mitigation of Drug Resistance in Streptococcus Species
}

\author{
Ammar A.M.1, El-Naenaeey E.Y.M.', Abd El-Aziz N.K. ${ }^{1}$ and Elazazy A.A. ${ }^{2}$ \\ ${ }^{1}$ Department of Microbiology, Faculty of Veterinary Medicine, Zagazig University, Egypt. \\ 2*Abou Hamad Veterinary organization, Ministry of agriculture, Abou Hamad, Sharkia, Egypt
}

\section{A B S T R A C T}

During infection, S. agalactiae can form biofilms which is associated with increased antimicrobial resistance. Additionally, bacteria when present in a biofilm , are resistant to various physicochemical stresses. Therefore, this study is aimed to determine the in vitro anti biofilm activities of cinnamon oil and/or silver nanoparticles and augmentin against multidrug resistant $S$. agalactiae isolates recovered from clinical mastitic dairy cattle. Antimicrobial susceptibility testing of 146 Streptococci isolates revealed that $42.5 \%$ (62/146) of Streptococci isolates exhibited a feature of multidrug resistance (MDR), being resistant to more than 3 antibiotics of different classes. Cinnamon oil, silver nanoparticles and augmentin exhibited marked inhibitory activities against $S$. agalactiae isolates with inhibition zone diameters up to $40 \mathrm{~mm}, 35 \mathrm{~mm}$ and $38 \mathrm{~mm}$ respectively. Besides, broth microdilution test of cinnamon oil revealed maximum activities against the tested isolates with minimum inhibitory concentrations (MICs) up to $0.0025 \mu \mathrm{g} / \mathrm{mL}$. The combination of cinnamon oil and silver nanoparticles combination gave the best result as the MIC values have been reduced to 4 folds. The cinnamon oil alone was capable of reducing the number of cells just after $4 \mathrm{~h}$ according to time killing assay.

The above results highlight the hopeful antibacterial and antibiofilm features of cinnamon oil and silver nanoparticles in the treatment of emergent resistant $S$. agalactiae mastitic infections.

Key words: S. agalactiae, Biofilm, Antibiofilm, AgNPs, Cinnamon

(http://www.bvmj.bu.edu.eg)

(BVMJ-35(2): 393-412, 2018)

\section{INTRODUCTION}

Streptococcus agalactiae (group B streptococci, GBS) is a noteworthy infectious mastitis pathogen where it causes subclinical and mellow direct clinical mastitis in dairy cows, resulting in critical financial misfortunes dairy ranchers (Keefe, 1997). This microorganism inadequately gets by in nature, yet can persevere inconclusively 
inside the mammary organ and could be transmitted to solid dairy animals through poor draining cleanliness. Execution of the standard mastitis aversion program has annihilated $S$. agalactiae from a few nations in Western Europe (Merl et al., 2003; Zadoks and Fitzpatrick, 2009). During the last decade, key virulence factors of group B Streptococci concerned with the survival, spread and persistence of the bacterium within the host (Nizet and Rubens, 2000 and Spellerberg, 2000). Colonization and infection of target tissues of GBS required the capacity of these bacteria to adhere and to keep on mucosal epithelial surfaces then, the formation of biofilm like communities could facilitate microbial survival and propagation by enhancing resistance to host defenses and nutrient lack (Melchior et al., 2006; Raza et al., 2013 and Rosini and Margarit, 2015). Microscopic organisms inside biofilms have expanded protection from antimicrobial specialists. In addition, the creation of biofilms was corresponded with pathogenicity and destructiveness of microscopic organisms (Saginur et al. (2006). Natural drugs have been critical wellsprings of items for the creating nations in treating basic irresistible ailments and defeat the issues of opposition and reactions of the as of now accessible antimicrobial specialists (Kianbakht and Jahaniani , 2003). Various in vitro thinks about have revealed the utilization of plant separates in mix with anti-infection agents, with critical decrease in the MICs of the anti- toxins against some safe strains (Darwish et al., 2002; Al-hebshi et al., 2006 and Betoni et al., 2006). Silver nano particles (AgNPs) utilized as antimicrobial agents, especially against multidrug safe microscopic organisms (Li et al., 2010; Cardozo et al., 2013 and Theophel et al., 2014). Additive substance or synergistic antibacterial impacts of silver nano particles joined with elective methodologies for treatment of obstruction (eugenol, phenazine-1-carboxamide, and cinnamaldehyde) and regular (ampicillin, kanamycin, erythromycin, chloramphenicol, amoxicillin, ciprofloxacin, and moxifloxacin) antimicrobial specialists (Ghosh et al., 2013; Theophel et al., 2014 and Biasi-Garbin et al., 2015). In the present study, we give evidence that GBS detaches can shaped biofilms on nonliving and living surfaces and sort 2a-pili are associated with biofilm development making more bond capacity and protection from antimicrobial agents utilized. Thus, we propose a potential novel technique to repress bacterial grip, antibacterial resistance and to prevent associated diseases.

\section{MATERIALS AND METHODS}

Clinical samples

Two hundred milk samples were randomly collected from mastitic dairy cattle showing decreased milk yield with pus descended in milk, bloody or clotted milk. Out of them, one hundred and six $(n=106)$ were obtained from different dairy farms from different Governorates in Egypt, while 94 samples were collected from sporadic cases in 
Sharqia Governorate. Sampling was done during the period from September 2015 to January 2016 with no history of antibiotic application during sample collection. Samples were aseptically collected in sterile screw capped bottles. The samples were transported in an ice box and bacteriological- examination was performed within $24 \mathrm{~h}$.

\section{Phenotypic characterization of Streptococci} isolates

Primary isolation and serotyping of streptococcal isolates was carried out onto Edward's agar medium (Oxoid, Hampshire, England, UK). Single, well-isolated colony from overnight cultures was subcultured onto blood agar for testing their haemolytic patterns (Edwards, 1933). The isolates were identified by standard bacteriological methods including cultural characteristics, Gram's stain and biochemical tests such as catalase, CAMP, sodium hippurate and esculin hydrolysis tests (Ayers and Rupp, 1922; Christie et al., 1944 and Hardie , 1986). Serotyping of the isolates was done in the Serology Unit, Animal Health Research Institute, Dokki, Giza, Egypt using commercial antisera (Oxoid, UK) according to the manufacturer's instructions.

Genotypic characterization of S. agalactiae

Genomic DNA was extracted from phenotypic streptococci isolates by using the QIAamp DNA Mini kit (Qiagen, GmbH, Germany) according to the manufacturer's instructions. Oligonucleotide primers for streptococci genus specific gene (tuf),
5'GTACAGTTG CTTCA GGACGTATC-3' and 5'-ACGTTCGATTTCATCACGTTG -3' (Ke et al., 2000) and S. agalactiae species specific gene $(c f b)$, 5'TTTCACCAGCTGTATTAGAAGTA-3' and 5'-GTTCCCTGAA CAT TATCTTTGAT -3') (Picard et al., 2004) were used. PCR amplifications were performed with a PTC$100{ }^{\mathrm{TM}}$ programmable thermal cycler (MJ Research Inc., Waltham, USA) in a total reaction volume of $25 \mu \mathrm{L}$ consisting of 12.5 $\mu \mathrm{L}$ of Emerald Amp GT PCR Master Mix (2X) (Fermentas, Inc. Hanover, USA), $1 \mu \mathrm{L}$ of each primer (Sigma Aldrich, Co., St. Louis, USA), $6 \mu \mathrm{L}$ template DNA and the volume was completed to $50 \mu \mathrm{L}$ by nuclease-free water. The amplification condition for tuf and $c f b$ primers were performed as following thermal cycling condition sets: initial denaturation at $94^{\circ} \mathrm{C}$ for $5 \mathrm{~min}, 35$ cycles of amplification (secondary denaturation at $94^{\circ} \mathrm{C}$ for $30 \mathrm{sec}$, annealing at $50^{\circ} \mathrm{C}$ for $30 \mathrm{sec}$ for $t u f$ while $c f b$ primer at $55^{\circ} \mathrm{C}$ for $30 \mathrm{sec}$ and extension at $72^{\circ} \mathrm{C}$ for $30 \mathrm{sec}$ ) and a final extension step at $72^{\circ} \mathrm{C}$ for $7 \mathrm{~min}$. An aliquot of each amplicon was loaded on $1.5 \%$ agarose gel (Sigma-Aldrich, Co., St. Louis, MO, USA) containing $0.5 \mu \mathrm{g} / \mathrm{mL}$ ethidium bromide (Sigma-Aldrich, Co., St. Louis, MO, USA)( Sambrook et al., 1989). A 100 bp DNA ladder (Fermentas, Inc. Hanover, USA) was used as a molecular weight standard. The amplified DNAs were electrophoresed at 100 $\mathrm{V}$ for 60 minutes on a mini horizontal electrophoresis unit (Bio-Rad, USA). The gel 
was then visualized and photographed under an UV transilluminator (Spectroline, Westbury, USA).For each PCR experiment, appropriate positive and negative controls were included.

\section{Antimicrobial susceptibility testing}

-Disc diffusion method

Susceptibility of streptococci isolates to various antimicrobials was evaluated by Kirby-Bauer disc diffusion test (Bauer et al., 1966) and the results were evaluated according to the guidelines of Clinical and Laboratory Standards Institute (CLSI, 2014). Antimicrobial discs (Oxoid, Hampshire, England, UK) including amoxicillin $(25 \mu \mathrm{g})$, amoxicillin/clavulanic acid $(20 / 10 \mu \mathrm{g})$, cloxicillin $(1 \mu \mathrm{g})$, cefoperazone $(75 \mu \mathrm{g})$, ceftriaxone $(30 \mu \mathrm{g})$, cephalexin $(30 \mu \mathrm{g})$, impenem(10 $\mu \mathrm{g})$, streptomycin $(10 \mu \mathrm{g})$, ciprofloxacin (5 $\quad \mu \mathrm{g})$, trimethoprim/ sulphamethoxazole $\quad(23.75 / 1.25 \quad \mu \mathrm{g})$, tetracycline $(30 \mu \mathrm{g})$, clindamycin $(2 \mu \mathrm{g})$ and erythromycin $(15 \mu \mathrm{g})$ were used.

\section{Agar well diffusion method}

The antimicrobial activities of 7 MDR S. agalactiae isolates against cinnamon oil(Sigma Aldrish, Germany), AgNPs (Nakaa company, Egypt) and augmentin (GlaxoSmithKline, USA) were applied using agar well diffusion method (Valgas et al. (2007). It was performed using $18 \mathrm{~h}$ cultures in $10 \mathrm{~mL}$ Müller Hinton broth adjusted approximately to $1-1.5 \times 10^{8} \mathrm{CFU} / \mathrm{mL}$. The bacterial suspension was spread over the plates of Müller-Hinton agar (Oxoid,
Hampshire, England, UK) using a sterile cotton swab in order to get a uniform microbial growth on both control and test plates. The used essential oil was dissolved in $10 \%$ aqueous dimethyl-sulfoxide (DMSO) under aseptic conditions. A well was made in MHA and filled with $100 \mu \mathrm{L}$ of the respective cinnamon oil prepared in DMSO, while silver nanoparticles and augmentin drug were dissolved in sterile distilled water then the agar surface was inoculated with the culture. A well was filled with aqueous DMSO as negative control. The plates were left for 30 minutes at room temperature to allow the diffusion of oil and other agents and then were incubated at $37^{\circ} \mathrm{C}$ for $24 \mathrm{~h}$. After the incubation period, the zones of inhibition around the wells were measured and recorded. Minimum inhibitory concentration

The minimum inhibitory concentrations (MIC) of silver nanoparticles, augmentin drug and cinnamon oil were determined using the broth micro-dilution method (Kwiecinski et al., 2009). The inoculum size was approximately prepared as $5 \times 10^{5} \mathrm{CFU} / \mathrm{mL}$. A double fold serial dilution was made for each reagent in customdesigned 96-well panels (Corning, New York, USA) starting from a concentration of $1024 \mu \mathrm{g} / \mathrm{mL}$. Controls of broth medium with the microorganism or reagent alone were included as positive and negative controls. The microtitre plates were incubated at $37^{\circ} \mathrm{C}$ for $24 \mathrm{~h}$. The first dilution with no microbial growth was recorded as MIC of the reagent. 
Subsequently, aliquots from each well were plated onto Müller Hinton agar and incubated at $37^{\circ} \mathrm{C}$ for $24 \mathrm{~h}$ to determine the $\mathrm{MBC}$ (minimum bactericidal concentration) of the reagents. The plates were checked for growth of bacterial colonies and MBCs were evaluated as the lowest concentration at which no growth was observed on the plates.

\section{Time kill curve assay}

Planktonic cells of $S$. agalactiae isolates $\left(1-5 \times 10^{5} \mathrm{CFU} / \mathrm{mL}\right)$ were incubated in MHB containing MIC levels of cinnamon, augmentin and silver nanoparticles. At determined time points $(0,1,2,4,6,8,10$, and $24 \mathrm{~h}$ ), aliquots were aseptically transferred to MHA plus 5\% sheep blood plates and the colony forming unit counts were determined after incubation at $37^{\circ} \mathrm{C}$ for 24h (Biasi-Garbin et al., 2015).

Phenotypic detection of biofilm formation by S. agalactiae

-Congo red agar (Reid, 1999)

Congo red agar plates were inoculated with test organisms and incubated at $37^{\circ} \mathrm{C}$ for $24 \mathrm{~h}$ aerobically. Black colonies with a dry crystalline consistency indicated biofilm production.

-Quantitive detection of biofilm by microtiter plate method

The biofilm assay was performed using flat-bottom micro titer plates as described previously (Tendolkar et al., 2004). S. agalactiae isolates were grown at $37^{\circ} \mathrm{C}$ in tryptic soy broth (oxoid, Uk). The bacterial cells were then pelleted at $6,000 \mathrm{xg}$ for 10 min, and the cell pellet were resuspended in 5 $\mathrm{mL}$ of fresh medium. The optical densities (ODs) of the bacterial suspensions were measured using spectrophotometer (Jenway Ltd., Essex, UK) and normalized to an absorbance of 1.00 at $600 \mathrm{~nm}$. The cultures were diluted 1:40 in fresh TSB then $200 \mu \mathrm{L}$ of cells were dispensed into 12 wells in a single row of a sterile 96-well flat-bottom polystyrene micro titer plate. After incubation at $37^{\circ} \mathrm{C}$ for $24 \mathrm{~h}$, the planktonic cells were aspirated and the wells were washed three times with sterile phosphate-buffered saline (PBS). The plates were inverted and allowed to dry for $1 \mathrm{~h}$ at room temperature. For biofilm quantification, $200 \mu \mathrm{L}$ of $0.1 \%$ aqueous crystal violet solution was added to each well, and the plates were allowed to stand for 15 min. The wells were subsequently washed three times with sterile PBS to wash off the excess crystal violet. Crystal violet bound to the biofilms was extracted with $200 \mu \mathrm{L}$ of an 80:20 (v/v) mixture of ethyl alcohol and acetone, and the absorbance of the extracted crystal violet was measured at $595 \mathrm{~nm}$ on ELISA reader (stat fax 2010,Germany).As a control crystal violet binding was measured for wells exposed only to the medium with no bacteria. All biofilm assays were performed in triplicate. Interpretation of biofilm production was according to the criteria described previously (Stepanovi et al., 2007). Based on these criteria, optical density cut-off value (ODc) is defined as: average OD of negative control+ $3 \times \mathrm{SD}$ (standard deviation)of 
negative control, and the biofilms producers are categorized as: $\mathrm{OD} \leq \mathrm{ODc}=$ not a biofilm producer , ODc $<\mathrm{OD} \leq 2 \mathrm{x}$ ODc=weak biofilm producer, $2 \mathrm{x}$ ODc $<\mathrm{OD} \leq 4 \mathrm{x}$ ODc $=$ moderate biofilm producer, $4 \mathrm{x}$ ODc $<\mathrm{OD}=$ strong biofilm producer.

Antibiofilm activity of cinnamon, augmentin and silver nanoparticles

For analysis of cinnamon, augmentin and silver nanoparticles effect on mature biofilm, $20 \mu \mathrm{L}$ of each cell suspension was added to each well containing $180 \mu \mathrm{L}$ of trypticase soya broth (TSB). After $24 \mathrm{~h}$ of biofilm formation, the medium was aspirated off and each well was rinsed with sterile PBS. A $200 \mu \mathrm{L}$ aliquots of TSB containing different concentrations (double fold serial dilution)of each type (cinnamon, augmentin and silver nanoparticles) were added and the plates were incubated for another $24 \mathrm{~h}$ with alternative substances free wells and biofilm-free wells included as positive and negative controls, respectively. The optical density was measured at $595 \mathrm{~nm}$ with an ELISA reader. Experiments were carried out in triplicate manner (Shafreen et al., 2011). The reduction of biofilm formation of each clinical strain was expressed as antibiofilm activity (\%), calculated as follows: (OD control-OD sample / OD control) $\times 100$.

\section{Checkerboard method}

Two fold serial dilutions of the compounds were prepared in TSB and placed on96-well micro titer plates. Bacteria $\left(1.0 \times 10^{5}\right.$ cells $)$ were grown with cinnamon or silver nanoparticles or augmentin individually and in combinations at $37^{\circ} \mathrm{C}$ for $24 \mathrm{~h}$. The interactions of the two compounds were analyzed by the fractional inhibitory concentration index (FICI), which is defined as the sum of FIC cinnamon and FIC silver nanoparticles or augmentin. FIC of the material is the concentration that kills when being used in combination with another divided by the concentration that has same effect when used individually (Yadav et al., 2013).

\section{RESULTS}

Isolation and identification of streptococcal mastitis

Bacteriological analysis of 200 milk samples randomly collected from mastitic milking cattle either from dairy farms from different Governorates in Egypt or sporadic cases from Sharqia Governorate revealed that Streptococcus spp. were recorded in 146 samples (73\%) Table(1).On Edward's agar media, Streptococcus spp. showed dew drop colorless colonies, among them, 38 (26\%) were $\alpha$ haemolytic, $75(51.3 \%)$ were $\beta$ haemolytic and 33 (22.6\%) were $\gamma$ haemolytic when the media was supplied by $5 \%$ sheep blood. Among the $\beta$ haemolytic isolates, 27 (18.5\%) produced CAMP reaction that may be identified as either $S$. agalactiae or $S$. uberis. Biochemical characteristics of bacterial isolates identified them simply. Sodium hippurate test identified $S$. agalactiae and $S$. uberis from other streptococci isolates 
which gave positive reaction (violet ring) $(30 / 146 ; 20.5 \%)$ while other streptococci were sodium hippurate negative (yellow ring) $(116 / 146 ; 79.5 \%)$.

In addition, esculin hydrolysis biochemical test was used for identification of S. uberis and E. faecalis (63/146; 43.2\%), which produced black colonies when cultivated on bile esculin agar due to esculin hydrolysis. For differentiation between them, the isolates were cultured on MacConkey's agar media, on which $S$. uberis was negative $(23 / 63 ; 36.5 \%)$, while 40 isolates $(63.5 \%)$ grew which were then identified as $E$. faecalis.

All bile esculin negative Streptococci isolates $(83 / 146)$ were tested for their susceptibility to bacitracin antibiotic disc. The results recorded that $45 / 83(54.22 \%)$ were sensitive for bacitracin ensuring them as $S$. pyogenes. In contrary, $3883(45.78 \%)$ of the isolates were bacitracin resistant and seven isolates of them were recognized by CAMP positive reaction, $\beta$-haemolysis on blood agar and sodium hippurate hydrolysis test positive as $S$. agalactiae isolates with a percentage of $4.79 \%$ of the total recovered isolates. Serological identification was applied for the unidentified isolates $(n=31)$ and the results revealed 25(80.6\%) Group C streptococci and 6 (19.4\%) Group D non enterococcus Streptococci.

Conventional PCR was done for molecular identification of streptococci isolates $(n=30)$ which were $\beta$ haemolytic and positive sodium hippurate test and the results revealed $7 \mathrm{~S}$. agalactiae isolates with amplicons of $153 \mathrm{pb}$ Fig (1\&2).

\section{Antimicrobial susceptibility testing}

All streptococci isolates were tested for their susceptibility to different antimicrobial agents of several classes. Absolute susceptibility was observed for impenem followed by ciprofloxacin (73\%) which could be used as a drug of choice for treatment; meanwhile, $100 \%$ of streptococci isolates were resistant to streptomycin, clindamycin, ceftriaxone, cephalexin and cefepime and cloxacillin. Additionally, more than half of isolates were resistant to amoxicillin clavulanic acid (91.7\%), 86\% were resistant to tetracycline, $80 \%$ were resistant to amoxicillin, $79 \%$ were resistant to erythromycin and $54.7 \%$ were resistant to sulfamethoxazole-trimethoprim. streptococci isolates were MDR. The higher percentage of resistance to antimicrobials classes was documented for 5 classes (62/146; $42.5 \%$ ).

Antimicrobial activities of cinnamon oil, silver nanoparticles and augmentin.

The effectiveness of the essential oil was confirmed by agar well diffusion assay and its inhibition zone diameter was measured. It was observed that DMSO control wells revealed no inhibition for all examined isolates. Cinnamon oil exhibited marked inhibitory activities against $S$. agalactiae isolates with inhibition zones` diameters ranged between $36-40 \mathrm{~mm}$. Silver 
nanoparticles exhibited inhibitory activities against $S$. agalactiae isolates but less than cinnamon oil with inhibition zones` diameter ranged between 28-38 mm. Also, Amoxicillin clavuolanic exhibited inhibitory activities with inhibition zones` diameters ranged between $36-40 \mathrm{~mm}$.

Minimum inhibitory concentrations and minimum bactericidal concentrations of cinnamon oil, silver nano particles and augmentin using broth microdilution assay were variable. Interestingly, cinnamon oil with $10.24 \mu \mathrm{g} / \mathrm{mL}$ as stock concentration recorded the lowest MIC values (up to $0.0025 \mu \mathrm{g} / \mathrm{mL}$ )while MICs of $0.25 \mu \mathrm{g} / \mathrm{mL}$ and $8 \mu \mathrm{g} / \mathrm{mL}$ were recorded for augmentin and silver nanoparticles, respectively when starting with a stock solution of $512 \mu \mathrm{g} / \mathrm{mL}$. The more efficient agent against $S$. agalactiae was cinnamon as its values were ranged from $0.04-0.0025 \mu \mathrm{g} / \mathrm{mL}$, then augmentin (2$0.25 \mu \mathrm{g} / \mathrm{mL}$ ) and at the end silver nanoparticles $(16-8 \mu \mathrm{g} / \mathrm{mL})$.

\section{Combination between cinnamon, augmentin} and silver nanoparticles alternatively

Two types of treatments for $S$. agalactiae isolates on microtiterplate were used which showed either additive, synergistic, antagonistic or no interaction between them (Table 2). When the two compounds were combined, the MIC values of cinnamon and silver nanoparticles reduced 4folds to be $0.000625-0.0025 \mu \mathrm{g} / \mathrm{mL}, 0.3-$ $0.125 \mu \mathrm{g} / \mathrm{mL}$, respectively. In addition, the MIC values of augmentin and silver nanoparticles reduced 4folds to be 0.125 $0.3 \mu \mathrm{g} / \mathrm{mL}$ and the MIC values of both cinnamon and augmentin decreased 4 folds $(0.00015 / 0.0083 \mu \mathrm{g} / \mathrm{mL})$.

Time kill curve assay

Synergistic activities of cinnamon oil, silver nanoparticles and augmentin alternatively (previously shown by broth dilution assays) were examined in a multitime point assay and the time-response curves were plotted. Bacteria were inhibited to various degrees in the presence of cinnamon, silver nanoparticles and augmentin. When treated with cinnamon at $0.0025 \mu \mathrm{g} / \mathrm{mL}$, AgNPs at $16 \mu \mathrm{g} / \mathrm{mL}$ and augmentin at 0 . $25 \mu \mathrm{g} / \mathrm{mL}$, complete inhibition of $S$. agalactiae growth after $24 \mathrm{~h}$ exposure was found. However when the bacteria were exposed to cinnamon + AgNPs, $100 \%$ inhibition was achieved within $10 \mathrm{~h}$ of exposure, upon exposure to cinnamon+ augmentin, $100 \%$ inhibition was achieved within 12 h., while upon exposure to AgNPs+augmentin, $100 \%$ inhibition was achieved. This data suggested the cinnamon oil enhanced anti-bacterial effect of AgNPs. The synergistic interaction was observed after 4 hour incubation where there were decreasing in $S$. agalactiae growth than seen in AgNPs alone.

Phenotypic detection of biofilm by Congo red agar

S. agalactiae isolates $(\mathrm{n}=7)$ were cultured on Congo red agar for production of biofilm. Biofilm producing isolates (5/7, 
$71.4 \%$ ) could convert red color of media into black color due to consuming the sucrose in the media.

Quantitative detection of biofilm by $S$. agalactiae isolates

On Trypticase soya broth, $7 \mathrm{~S}$. agalactiae isolates were cultured for biofilm production quantitatively. Five $(71.4 \%) S$. agalactiae produced week biofilm, while moderate and strong biofilm producing isolates were also recorded one for each $(14.3 \%)$.

Antibiofilm activities of cinnamon oil, augmentin and silver nanoparticles

Different concentrations of cinnamon oil, augmentin or silver nanoparticles against S. agalactiae were applied as antibiofilm and measured by the ELISA reader. In comparison with biofilm of each $S$. agalactiae isolate, biofilm was inhibited by different concentrations of cinnamon with variations (21-98\%), most of isolates were inhibited at different concentrations $(51.2-0.025 \mu \mathrm{g} / \mathrm{mL})$ so, cinnamon oil was effective against biofilm formation by $S$. agalactiae.

Combination between the antibacterial agents as antibiofilm

Combinations of cinnamon oil, augmentin and or silver nanoparticles were applied to increase their efficacy to be used as antibiofilm With the combination of cinnamon oil and augmentin, most of isolates were inhibited at concentration of 32-64 $\mu \mathrm{g} / \mathrm{mL}$, so this combination was less effective than cinnamon oil or augmentin alone in treatment of biofilm formation by $S$. agalactiae. In combination of silver nanoparticles and cinnamon oil, most of isolates were inhibited at concentrations of $0.25-0.125 \mu \mathrm{g} / \mathrm{mL}$, so this combination was more effective than each of cinnamon or silver nanoparticles alone in treatment of biofilm formation by $S$. agalactiae. In combination of silver nanoparticles and augmentin, most of isolates were inhibited at concentration of $1 / 1 \mu \mathrm{g} / \mathrm{mL}$, so this combination was more effective than each of them alone in treatment of biofilm formation by $S$. agalactiae. 
Table (1): Incidence of Streptococcus species in clinically mastitic dairy cattle in different localities in Egypt

\begin{tabular}{|c|c|c|c|c|c|c|c|c|}
\hline \multicolumn{2}{|c|}{ Source of samples(No) } & $\begin{array}{l}\text { Positive growth } \\
\text { on Edward`s } \\
\text { media }^{\mathrm{a}}\end{array}$ & S. agalactiae ${ }^{b}$ & S. uberis ${ }^{b}$ & $\begin{array}{c}\text { S.pyogene } \\
s^{b}\end{array}$ & Enterococcus $^{b}$ & $\begin{array}{c}\text { Group } \\
\text { C streptococci } \\
(\text { S. dysagalactiae })^{b}\end{array}$ & $\begin{array}{l}\text { Group D non- } \\
\text { enterococcus, } \\
\text { streptococci }^{b}\end{array}$ \\
\hline Sporadic & Belbies (19) & $14(73.68)$ & $1(7.14)$ & $2(14.29)$ & $4(28.57)$ & $4(28.57)$ & $3(21.43)$ & $0(0.00)$ \\
\hline \multirow{4}{*}{ Sharkia } & Awladsief (38) & $24(63.16)$ & $0(0.00)$ & $1(4.17)$ & $8(33.33)$ & $10(41.67)$ & $3(12.50)$ & $2(8.33)$ \\
\hline & Bordien (27) & $1(3.70)$ & $0(0.00)$ & $0(0.00)$ & $0(0.00)$ & $0(0.00)$ & $0(0.00)$ & $1(100.00)$ \\
\hline & Abohamad (3) & $1(33.33)$ & $0(0.00)$ & $0(0.00)$ & $0(0.00)$ & $0(0.00)$ & $0(0.00)$ & $1(100.00)$ \\
\hline & Diarbnegm (7) & $3(42.86)$ & $0(0.00)$ & $0(0.00)$ & $1(33.33)$ & $0(0.00)$ & $2(66.67)$ & $0(0.00)$ \\
\hline \multirow{2}{*}{$\begin{array}{l}\text { Farms } \\
\text { Sharkia }\end{array}$} & Mandoor (19) & $18(94.74)$ & $0(0.00)$ & $7(38.89)$ & $4(22.22)$ & $5(27.78)$ & $2(11.11)$ & $0(0.00)$ \\
\hline & Alharaky (16) & $16(100.00)$ & $2(12.50)$ & $2(12.50)$ & $4(25.00)$ & $8(50.00)$ & $0(0.00)$ & $0(0.00)$ \\
\hline Giza & Alalamia (10) & $10(100.00)$ & $1(10.00)$ & $3(30.00)$ & $3(30.00)$ & $2(20.00)$ & $1(10.00)$ & $0(0.00)$ \\
\hline \multirow[t]{2}{*}{ Suez } & Suez (15) & $15(100.00)$ & $0(0.00)$ & $0(0.00)$ & $1(6.67)$ & $5(33.33)$ & $8(53.33)$ & $1(6.67)$ \\
\hline & Atefsalem (11) & $9(81.82)$ & $0(0.00)$ & $0(0.00)$ & $3(33.33)$ & $0(0.00)$ & $5(88.89)$ & $1(11.11)$ \\
\hline \multirow{3}{*}{ Alexandria } & Dina (17) & $17(100.00)$ & $1(5.88)$ & $5(29.41)$ & $8(47.06)$ & $3(41.18)$ & $0(55.56)$ & $0(0.00)$ \\
\hline & Talaat (8) & $8(100.00)$ & $0(0.00)$ & $3(37.50)$ & $2(25.00)$ & $2(25.00)$ & $1(12.50)$ & $0(0.00)$ \\
\hline & Said elalfy (10) & $10(100.00)$ & $2(20.00)$ & $0(0.00)$ & $7(70.00)$ & 1.(10.00) & $0(0.00)$ & $0(0.00)$ \\
\hline Total & 200 & $146(73.00)$ & $7(4.79)$ & $23(15.75)$ & $45(30.82)$ & $40(27.40)$ & $25(17.12)$ & $6(4.11)$ \\
\hline
\end{tabular}

No: Number. Data are represented by No $(\%)$.

a:Percentages were calculated according to number of mastitis milk samples.

b:Percentages were calculated according to number of positive Streptococci isolates on Edward's media 
Table 2: Results of checkerboard test for cinnamon and silver nanoparticles, cinnamon/augmentin and augmentin/ silver nanoparticles against $S$. agalactiae

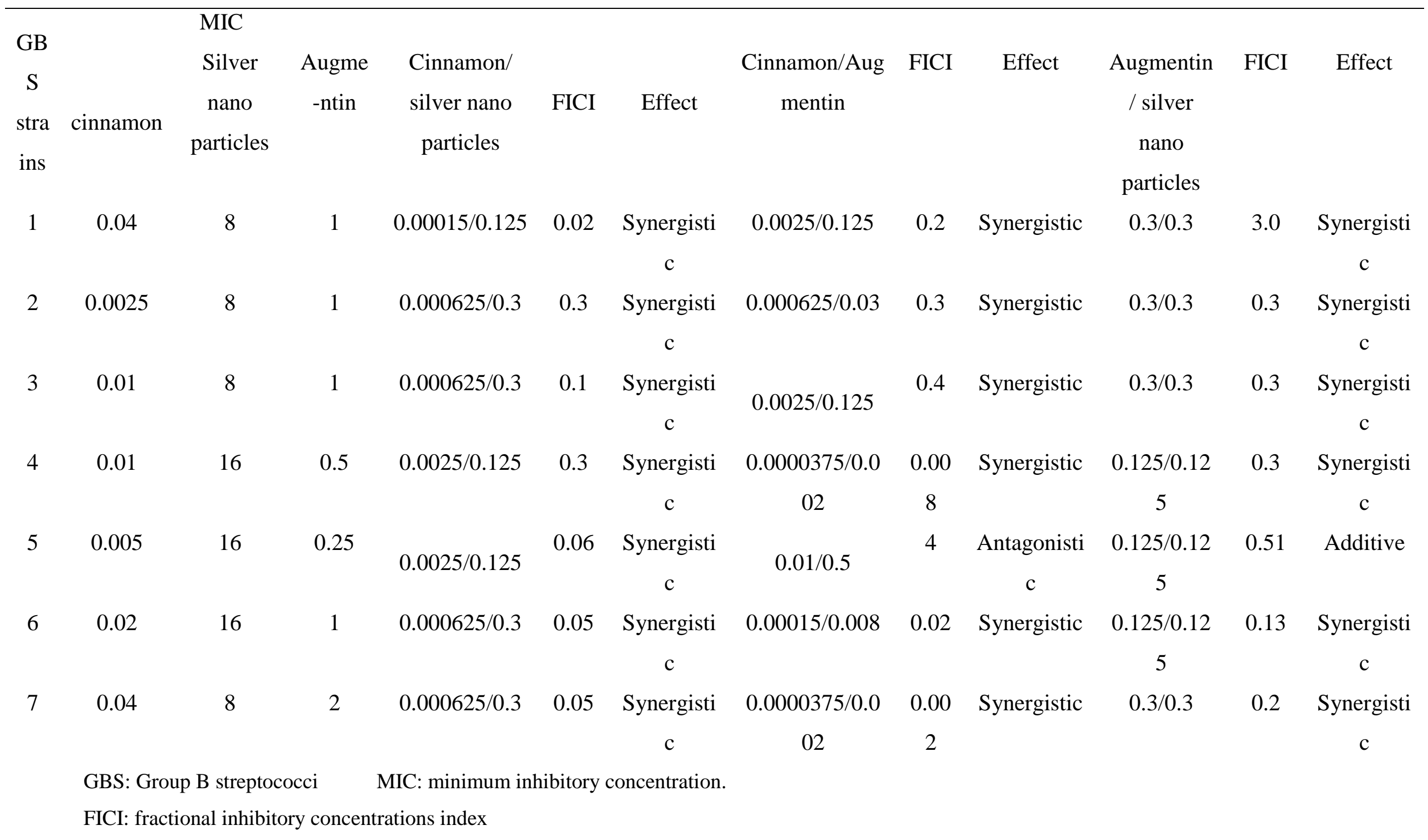




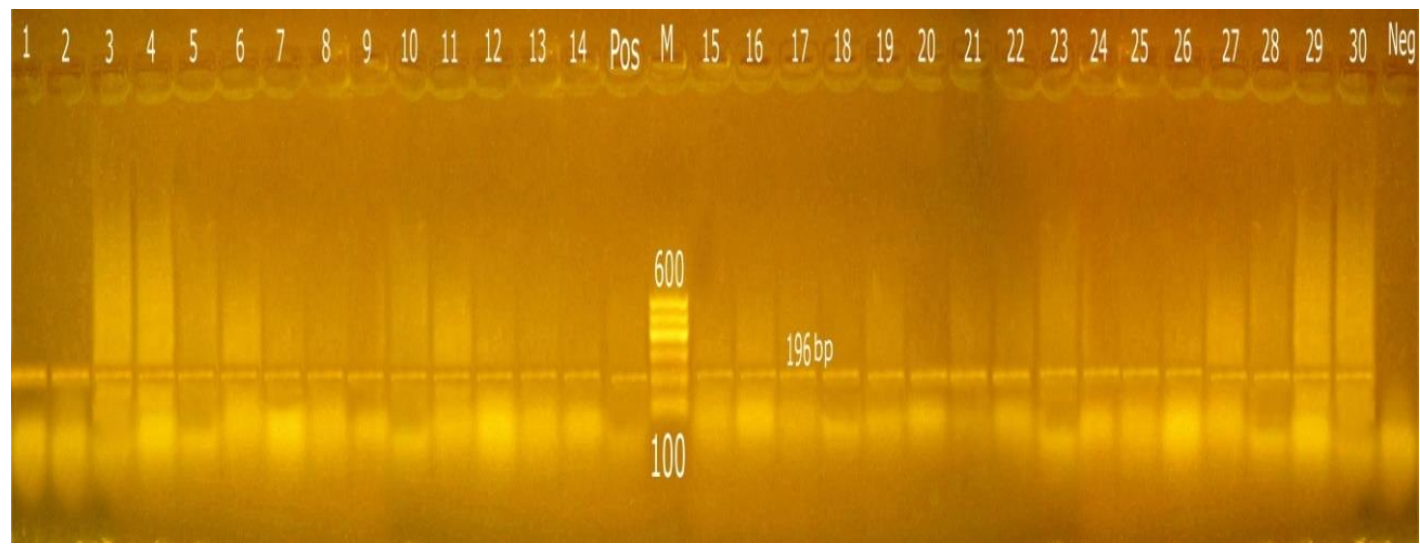

Fig. (1): PCR amplification of $196 \mathrm{bp}$ tuf gene of Streptococci isolated from bovine mastitis cases. Lane M: 100 bp DNA ladder"Marker", Lanes 1-30 were positive Streptococci isolate. Lane Pos: positive control, Lane Neg: negative control.

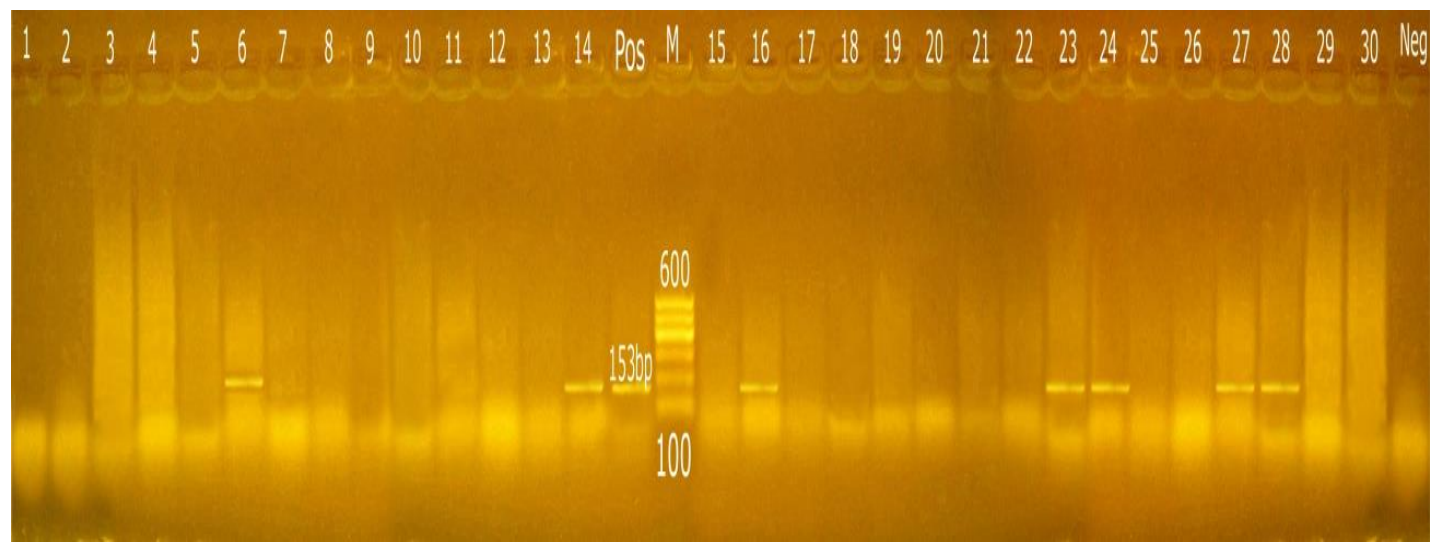

Fig. (2): PCR amplification of $c f b$ gene of $S$. agalactiae isolates. M: 100 bp ladder"Marker", lanes No. $6,14,16,23,24,27$ and 28 were positive, lane Neg: negative control, lane pos: positive control.

\section{DISCUSSION}

Streptococcus agalactiae is a noteworthy infectious pathogen causing clinical and subclinical mastitis. In spite of the fact that this bacterium has a short life expectancy in the earth, it can survive inconclusively inside the mammary organ as a commit pathogen of the udder, Both prompt decreasing milk production, crowds flare-ups, so this is of real significance for the dairy business. Projects to decrease the effect of $S$. agalactiae infection have been authorized in numerous nations over years as annihilation from a crowd may not be accomplished if $\mathrm{S}$. agalactiae ends up impervious to the antitoxin utilized, either by hereditary change or by creation of a covering to shield cells from the anti-microbial (Rosini and Margarit , 2015). Herein, Streptococci was recorded in 146 out of 200 examined milk samples $(73 \%)$. This is inconsonance with the study of 
Amosun et al., 2010) who detected Streptococci in milk samples with a percentage of $65 \%$. Indeed, in this study, the incidence of Streptococci was recorded as follow, E. faecalis (27.4\%), group D streptococci (21.2\%), group C streptococci (17.1\%), S. uberis (15.7\%), S. pyogenes $(13.7 \%)$ and S. agalactiae (4.7\%) which was agreed with Edyta Kaczorek et al., 2017)who reported that $S$. uberis $(39.3 \%), \quad S$. dysagalactiae $\quad(30.4 \%), \quad S$. agalactiae (20\%)and other streptococci (10.4\%) in Poland.

In this study, antimicrobial susceptibility testing of streptococci isolates revealed absolute susceptibility to impenem followed by ciprofloxacin $(73 \%)$ which could be used as a drug of choice for treatment; meanwhile, $100 \%$ of streptococci isolates were resistant to streptomycin, clindamycin, ceftriaxone, cephalexine, cefepime and cloxacillin. Additionally, more than half of isolates were resistant to amoxicillin clavulanic acid (91.7\%), while $86 \%$ of isolates were resistant to tetracycline, $80 \%$ were resistant to amoxicillin, $79 \%$ were resistant to erythromycin and finally $54.7 \%$ were resistant to sulfamethoxazoletrimethoprim, Less frequent resistance was reported by S. agalactiae (46.3\%), E. faecium (23.1\%) and S. equines $(20.0 \%)$ (Klimiene et al., 2011) was not agreed with the present study. Nonetheless, information from the investigation of Nam et al., 2009) was very high contrasted and a report from Sweden, which demonstrated $0 \%$ protection from oxytetracycline in S. uberis and S. agalactiae revealed by Gianneechini et al., 2002). The abnormal state of antibiotic medication opposition could be related with antibiotic medication use in Korea, in which the extent of antibiotic medications represented over half of the offers of antimicrobial operators for creatures (KFDA, 2003\&2004). $\quad \beta$ Lactams are known as the principal line antimicrobial operators while treating streptococcal udder contaminations (Denamiel et al., 2005). As a few examinations have illustrated (Erskine et al., 2002 and Gianneechini et al., 2002), cephalothin and penicillin were observed to be consistently successful against streptococcus separates, over $96 \%$ and $92 \%$ of secludes indicated susceptibilities to these 2 $\beta$-lactams, individually shown by Nam et al., 2009). Oxacillin indicated moderately low action contrasted and other $\beta$-lactams tried and the predominance of protection from oxacillin was lower than those of different examinations by Erskine et al. , 2002 and Rossitto et al., 2002). Other than $\beta$-lactams, erythromycin appeared to be the most dynamic antimicrobial specialist, and $28.6 \%$ of streptococcal separates demonstrated protection from this medication. This finding is like those of past reports from France (21\%) (Gue'rin-Fauble' et al. 2002) and Argentina (27.6\%), (Denamiel et al., 2005) however considerably higher than that of an investigation on dairy crowds in Uruguay ( 0 
3\%) (Gianneechini et al.,2002 ). Level of erythromycin-safe S. uberis $(34.3 \%)$ seen by Nam et al., 2009 was like the finding in a report from the United States (31.9\%) (Erskine, 2002) however was significantly higher than that of a report from Finland, (Pitka“la“ et al., 2004) in which no S. uberis disengages were impervious to this medication. The prevalence of resistance to gentamycin and erythromycin was the most variable among the species that showed lower portions of resistance to gentamycin ranged between 20 to $42.4 \%$. Although S. agalactiae was susceptible to erythromycin, others showed various rates of resistance to this drug, ranging from $12.5 \%$ to $42.8 \%$ (Nam et al., 2009). while in this study a higher prevalence of resistance to erythromycin (79\%), streptomycin and clindamycin (100\%) in all species.

In this study, cinnamon oil exhibited marked inhibitory activities against $S$. agalactiae isolates with inhibition zone diameters up to $40 \mathrm{~mm}$ by agar well diffusion assay when using a concentration of $1024 \mu \mathrm{g} / \mathrm{mL}$. There were no reports of similar studies connected with antibacterial activity of cinnamnon oil against GBS in mastitis in Egypt. The cinnamon oil was active against Streptococcus mutans clinical strains at different concentrations: 100; 50; 25; 12.5 and $6.25 \%$ for which corresponding inhibit zones: 62; 51; 35; 21 and $16 \mathrm{~mm}$ were obtained. The authors applied disc-diffusion method using $50 \mu \mathrm{L}$ of the oil per $6 \mathrm{~mm}$ disc
Fani and Kohanteb , 2011). In this study, cinnamon oil showed antibacterial effect against $S$. agalactiae with MIC values ranged from0.04 to $0.0025 \mu \mathrm{g} / \mathrm{mL}$. In a study documented previously that both cinnamaldehyde and eugenol standards showed profound activity against both Streptococci spp. and Gram negative anaerobes, active concentration for both compounds ranged between $\left(\begin{array}{lll}0.15 & -0.8\end{array}\right.$ $\mu \mathrm{g} / \mathrm{mL}$ ) (Abidin et al., 2013). Additionally, the findings were reported on the activity of cinnamon bark oil against both Gram positive and Gram negative bacteria shown by Unlu et al., 2010)who agreed with the present study as streptococci was a Gram positive organism. In a previous research, the MIC values for cinnamon oil were $12.8 \mu \mathrm{g} / \mathrm{mL}$ for multidrug resistant and non-multidrug resistant streptococci clinical strains with the use of agar dilution method recorded by Fani and Kohanteb, 2011). In addition, the MIC values of the extracted oil from Cinnamomum zeylanicum against clinical strains of $S$. agalactiae isolated from the vagina and anus of women were between 0.125 and $1.0 \mu \mathrm{g} / \mathrm{mL}$ Monika et al., 2014).

Interestingly, the synergistic effect of cinnamon oil with silver nano particles and cinnamon oil with augmentin in this study was very effective as recorded in a previous study of Mohammad et al., 2016) which declared the profound synergistic effect of honey and cinnamon against S. mutans. The combination of eugenol with AgNPbio 
significantly reduced the MIC value of both compounds, and the calculated FICI indicated a synergistic effect between them against all GBS strains. At125 $\mu \mathrm{g} / \mathrm{mL}$, AgNPbio alone inhibited the growth of all GBS strains. When the two compounds were combined, the MIC values of eugenol and AgNPbio decreased 4to 8-fold and 4- to 256 fold, respectively Biasi-Garbi et al., 2015), and this combination similar to combination of cinnamon oil and silver nanoparticles in present study.

Silver nanoparticles synthesized by an eco friendly method using the filamentous fungus F. oxys-porum showed inhibitory activity against planktonic cells of all GBS strains in study reported previously by BiasiGarbi et al., 2015), this agreed with the present study that reported silver nanoparticles exhibited inhibitory activities but less than cinnamon oil against $S$. agalactiae strains with inhibition zone diameter of $35 \mathrm{~mm}$. Also, augmentin exhibited inhibitory activities with inhibition zone diameters up to $38 \mathrm{~mm}$. Silver nano particles (AgNPs)were a good bactericidal agents against multidrug resistance pathogens reported by Abdullah and Alwan , 2017), this idea was in consistent with other studies documented by Namasivayam et al., 2011 ; Amany et al., 2012) which reported that AgNPs were a better bactericidal for most multi drug bacterial resistance such as E. coli and $S$. aureus and all mentioned studies agreed with our study as S. aureus was Gram

positive organism and studies on $S$. agalactiae. The combination of these nanoparticles with several compounds has shown potent antimicrobial activity in different microbial species, including those displaying resistance to conventional antibiotics reported by Allahverdiyev et al., 2011; Cardozo et al., 2013; Ghosh et al.,2013; Herman and Herman, 2014). Additive or synergistic effect of essential oil component cinnamaldehyde with chemically synthesized silver nanoparticles against Gram-positive and Gram-negative bacteria has been reported elsewhere by Ghosh et al., 2013). In previous study Biasi-Garbin et al., 2015), eugenol also exhibited an antibacterial activity against biofilms of $S$. agalactiae, showing the ability to inhibit its formation as well as the viability of mature biofilm, under in vitro conditions ,this agreed with effect of cinnamon oil on biofilm.

\section{CONCLUSION}

The results obtained in this study demonstrated the bactericidal activity of cinnamon oil, silver nanoparticles and augmentin, in addition to the synergistic effect of cinnamon oil with AgNPs against planktonic cells of $S$. agalactiae. Furthermore, this compound inhibited biofilm formed on polystyrene.

\section{REFERENCES}

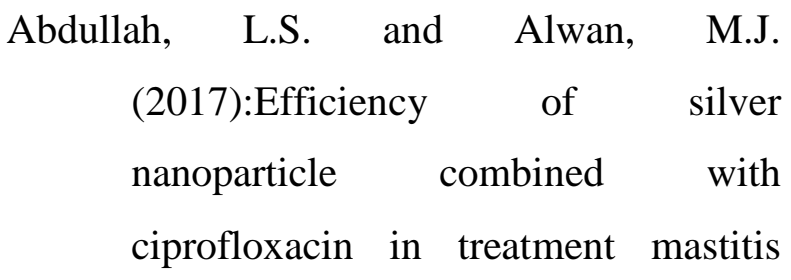


induced by E.coli $\mathrm{O} 157: \mathrm{H} 7$ isolated from milk of bovine mastitis ,Journal of Entomology and Zoology Studies 2017; 5(5): 1895-1902.

Abidin, Z.Z.; Said, S.M., Majid, F.A.A., Mustapha, W.A.W. and Jantan, I.(2013):Anti-Bacterial Activity of Cinnamon Oil onOral Pathogens, The Open Conference Proceedings Journal ,2013, 4, (Suppl-2, M4) 12-16.

Al-hebshi, N., Al-haroni, M. and Skaug, N. (2006): In vitro antimicrobial and resistance-modifying activities of aqueous crude khat extracts against oral microorganisms. Arch. Oral Biol. 51: 183-188.

Allahverdiyev, A.M., Kon, K.V., Abamor, E.S., Bagirova, M. and Rafailovich, M. (2011): "Coping with antibiotic resistance: combining nanoparticles with antibiotics and other antimicrobial agents, "Expert Review of Anti-Infective Therapy,vol.9,no.11 pp.1035-1052.

Amany, A., El-Rab, S.F., and Gad, F. (2012): Effect of reducing and protecting agents on size of silver nanoparticles and their anti-bacterial activity. Der Pharma Chemica. 2012; 4:53- 65.

Amosun, E.A., Ajuwape, A.T.P. and Adetosoye, A.I.(2010):Bovine Streptococcal Mastitis in Southwest and Northern States of Nigeria ,Afr. J. Biomed. Res. 13 , $33-37$.
Ayers, S.H. and Rupp, P. (1922): Differentiation of haemolytic Streptococci from human and bovine sources by the hydrolysis of sodium hippurate. J. Infect. Disease., 30:388.

Bauer, A.W., Kirby, W.M., Sherris, J.C. and Turk, M. (1966): Antibiotic susceptibility testing by the standared single disc method. A.M.J. Clin. Pathol, 45:493-446.

Betoni, J.E.C., Mantovani, R.P. ,Barbosa, L.N., Di-Stasi, L.C. and Fernandes, A. (2006): Synergism between plant extract and antimicrobial drugs used on Staphylococcus aureus diseases. Mem. Inst. Oswaldo Cruz. 101 No. 4.

Biasi-Garbin, R.P., Otaguiri, E.S., Morey, A.T., DaSilva, M.F., Morguette, A.E.B., Lancheros, C.A.C.et al., (2015): Effect of eugenol against Streptococcus agalactiae and synergistic interaction with biologically produced silver nanoparticles. Evid. Based Complement. Altern. Med. 861497. 10.1155 .

Cardozo, V.F., Oliveira, A.G., Nishio, E.K., Perugini, M.R.E., Andrade, C.G.T.J., Silveira, W.D.et al., (2013): Antibacterial activity of extracellular compounds produced by a Pseudomonas strain against methicillin-resistant Staphylococcus aureus (MRSA) strains. Ann. Clin. 
Microbiol. Antimicrob. 12:12. 10.1186/1476-0711-12-12 .

Christie, R., Atkins, N.E. and MunchPetersen, E. (1944): A note on a lytic phenomenon shown by group B Streptococci. Aust. J. Exp. Biol. Med. Sci. 22, 197-200.

Clinical and Laboratory Standards Institute(CLSI) (2014): Performance Standards for Antimicrobial Susceptibility Testing; 26th Edition. Wayne, PA: Clinical and Laboratory Standards Institute. CLSI document M100-S26.

Darwish, R.M., Aburjai, T., Al-Khalil, S. and Mahafzah, A. (2002): Screening of antibiotic resistant inhibitors from local plant materials against two different strains of Staphylococcus aureus. J. Ethnopharm. 79: 359-364.

Denamiel, G., Llorente, P., Carabella, M.et al.,(2005):Antimicrobial susceptibility of Streptococcus spp. Isolated from bovine mastitis in Argentina. J Vet Med B InfectDis Vet Public Health $52: 125-128$.

Edwards, S.J. (1933): J. Comp. Path. Therap., 46:211-217.

Erskine, R.J., Walker, R.D., Bolin, C.A. et al.,(2002): Trends in antibacterial susceptibility of mastitis pathogens during a seven-year period. J Dairy Sci 85:1111-1118.

Fani, M.M. and Kohanteb, J. 2011). Inhibitory activity of Cinnamon zeylanicumand Eucalyptus globules oils on Streptococcus mutans, Staphylococcus aureus, and Candidaspecies isolatedfrom patients with oral infections. Shiraz Univ. Dent. J. 11: 14-22.

Gianneechini, R.E., Concha, C. and Franklin, A. (2002):

Antimicrobial susceptibility of udder pathogens isolated fromdairy herds in the West Littoral Region of Uruguay. ActaVet Scand 43: 31-41.

Ghosh, I.N., Patil, S.D., Sharma, T.K., Srivastava, S.K., Pathania, R. and Navani, N. K. (2013): Synergistic action of cinnamaldehyde with silver nanoparticles against spore-forming bacteria: a case for judicious use of silver nanoparticles for antibacterial applications. Int. J. Nanomed.8, 47214731.

Gue'rin-Fauble'e, V., Tardy, F., Bouveron, C. and Carret, G.(2002): Antimicrobial susceptibility of Streptococcus species isolated from clinical mastitis in dairy cows. Int J Antimicrob Agents 19:219226.

Hardie, J.M.(1986): Genus Streptococcus. In: Sneath PHA, editor. Bergey's Manual of Systematic Bacteriology. Vol 2.Baltimore: Williams and Wilkins. p. 1043-71

Herman, A. and Herman, A.P.(2014): "Nanoparticles as antimicrobial agents: their toxicity and mechanisms 
of action,"Journal of Nanoscience and Nanotechnology,vol.14,no.1,pp.946$957,2014$.

Kaczorek, E. ,Małaczewska, J., Wójcik, R. and Siwicki, A.K. (2017): Biofilm production and other virulence factors in Streptococcus spp. isolated from clinical cases of bovine mastitis in Poland, BMC Vet Res. 2017; 13: 398.

Ke, D.; Ménard, C., Picard, F.J., Boissinot, M., Ouellette, M., Roy, P.H.; and Bergeron, M.G. (2000): Development of Conventional and Real-Time PCR Assays for the Rapid Detection of Group B Streptococci. Clinical Chemistry 46:3, 324-331.

Keefe, G.P. (1997): Streptococcus agalactiae mastitis: a review, Can Vet, 1. 38, 429-437.

Kianbakht, S. and Jahaniani, F. (2003): Evaluation of antibacterial activity of Tribulus terrestris L. growing in Iran. Iranian J. Pharm. Ther. 2: 22-24.

Klimiene, I., Ružauskas, M., S`pakauskas, V., Matusevic`ius, A., Mockeliunas, R., Pereckiene, A.; ButrimaiteAmbrozeviciene, C. and Virgailis, M.(2011):Antimicrobial resistance patternsto beta-lactams of grampositive cocci isolated from bovine mastitis in Lithuania, Polish Journal of Veterinary Sciences Vol. 14, No. 3 (2011), 467-472.

$\begin{array}{crrr}\text { Korean } & \text { Food and } & \text { Drug } \\ & \text { Administration(KFDA) } & \text { 2003and }\end{array}$

2004: Establishment of control system of antibiotics for livestock].KFDA, Seoul, Republic of Korea. In Korean Kwiecinski, J., Eick, S. and Wojcik, K.(2009):" Effects of tea tree(Melaleuca alternifolia) oil on Staphylococcus aureus in biofilms and stationary growth phase, "International Journal of Antimicrobial Agents ,vol.33,no.4,pp.343-347.

Li, W.R., Xie, X.B., Shi, Q.S., Zeng, H.Y., Ou-Yang, Y.S. and Chen, Y.B. (2010):Antibacterial activity and mechanism of silver nanoparticles on Escherichia coli. Appl. Microbiol. Biotechnol. 85, 1115-1122.

Melchior, M.B. ,Vaarkamp, H. and FinkGremmels, J. (2006): Biofilms: a role in recurrent mastitis infections? Vet $\mathbf{J}$ 171: 398-407.

Merl, K., Abdulmawjood, A., Lammler, C. and Zschock, M. (2003): Determination of epidemiological relationships of Streptococcus agalactiae isolated from bovine mastitis. FEMS Microbiol Lett; 226: 87-92.

Mohammad, B. R., Mohammad, N., Mohammad, K., Fateme, S.A. and Faeze, H.(2016):The synergistic effect of honey and cinnamon against Streptococcus mutans bacteria, Asian Pacific Journal of Tropical 
Biomedicine Volume 7, Issue 4, April 2017, Pages 314-320.

Monika, S., Maria, P., Jolanta, K. and Monika, B.(2014):Inhibitory Activity of Cinnamon Bark Oil on Group B Streptococci (GBS),TEOP 17 (5) 2014 $981-991$.

Namasivayam, S.K., Ganesh, S. and Avimanyu, B. (2011):Evaluation of anti-bacterial activity of silver nanoparticles synthesized from Candida glabrata and Fusarium oxysporum. Int J Med Res.; 1:131136.

Nam, H.M., Lim, S.K., Kang, H.M., Kim, J.M., Moon, J.S., Jang, K.C., Joo, Y.S., Kang, M.I. and Jung, S.C.(2009):Antimicrobial resistance of streptococci isolated from mastitic bovine milk samples in Korea,J Vet Diagn Invest 21:698-701.

Nizet, V. and Rubens, C.E.(2000): Pathogenic mechanisms and virulence factors of group b streptococci. In GramPositive Pathogens; ASM Press: Washington, DC, USA, 2000; pp. 125-136.

Picard, F.J., Ke, D., Boudreau, D.K., Boissinot, M., Huletsky, A., Richard, D.,Ouellette, M., Roy, P.H. and Bergeron, M.G. (2004):Use of tuf Sequences for Genus-Specific PCR Detection and Phylogenetic Analysis of 28 Streptococcal Species. JOURNAL OF CLINICAL
MICROBIOLOGY, Aug. 2004, p. 3686-3695.

Pitka"la", A., Haveri, M., Pyo“ra"la,"S. et al.,(2004): Bovin mastitis in Finland 2001,prevalence, distribution of bacteria, and antimicrobial resistance. J Dairy Sci 87:2433-2441.

Raza, A., Muhammad, G., Sharif, S. and Atta, A. (2013):Biofilm producing Staphylococcus aureus and bovine mastitis: a review. Mol Microbiol Res 3: $1-8$.

Reid, G.(1999): Biofilms in infectious disease and on medical devices. Int. $\mathrm{J}$. Antimic Ag; 11:223-6.

Rosini, R. and Margarit, I.(2015): Biofilm formation by Streptococcus agalactiae: influence of environmental conditions and implicated virulence factors, Front Cell Infect Microbiol. 10.3389 .

Rossitto, P.V., Ruiz, L., Kikuchi, Y.et al.,(2002): Antibiotic susceptibility patterns for environmental streptococci isolated from bovine mastitis in central California dairies. JDairy Sci 85:132-138.

Saginur, R., St Denis, M.; Ferris, W.et al.(2006):Multiple combination bactericidal testing of staphylococcal biofilms from implant-associated infections. Antimicrob Agents Chemother 2006; 50(1): 55-61.

Sambrook, J., Fritscgh, E.F.and Mentiates, T. (1989): Molecular coloning. A 
laboratory manual. Vol., Cold spring Harbor Laboratotry press.

Shafreen, R.M.B., Srinivasan, S., Manisankar, P. and Pan-dian, S.K.(2011): "Biofilm formation by Streptococcus pyogenes: modulation of exo poly saccharide by fluoro quinolone derivatives," Journal of Bioscience and Bioengineering,vol.112,no.4,pp.345350.

Spellerberg, B.(2000): Pathogenesis of Neonatal Streptococcus agalactiae infections. Microbes .Infect 2:17331742 .

Stepanovi, S., Vukovi, D., Hola, V., et al. (2007): Quantification of bio-film in microtiter plates: Overview of testing conditions and practical recommendations for assessment of biofilm production by staphylococci. Ac ta Pathol Microbiol Immunol Scand; 115(8): 891-899.

Tendolkar, P.M., Baghdayan, A.S., Gilmore, M.S. et al. (2004): Enterococcal Surface protein enhances biofilm formation by Enterococcus fecalis. Infect Immun; 72(10): 6032-6039.

Theophel, K., Schacht, V.J., Schlüter, M., Schnell,S., Stingu, C. S., Schaumann, R.et al., (2014): The importance of growth kinetic analysis in determining bacterial susceptibility against antibiotics and silver nanoparticles. Front. Microbiol. 5:544.
Unlu, M., Erge, E., Unlu, G.V. and Zeytinoglu, H.S. (2010):Vural. Composition, antimicrobial activity and in vitro cytotoxicity of essential oil from Cinnamomum zeylanicum Blume (Lauraceae). Food Chem Toxicol 2010; 48: 3274 -80.

Valgas, C., Machado de Souza, S., Smânia, E.F.A. and Smânia, A.J.R. ( 2007): Screening methods to determine antibacterial activity of natural products. Brazilian J. Microbiol., 38(2): 369-380.

Yadav, M.K., Park, S.W., Chae, S.W., Song, J.J. and Kim, H.C. (2013): Antimicrobial activities of Eugenia caryophyllata extract and its major chemical constituent eugenol against Streptococcus pneumoniae," Acta Pathologica, Microbiologica et Immunologica Scandinavica, vol.121, no.12, pp.1198-1206.

Zadoks, R.N. and Fitzpatrick, J.L.(2009): Changing trends in mastitis. Irish Veterinary Journal, 62, 59-70. 